\title{
PROTOTIPE PENGENALAN WAJAH DENGAN ALGORITMA FISHERFACE DAN VIOLA-JONES UNTUK SISTEM PENGUNCIAN PINTU MOBIL BERBASIS ANDROID
}

\section{Face Recognition Prototype Based on Android Use Fisherface and Viola- Jones Algorithms for Car Locking Door System}

\author{
Fadli Fairuz Ramadhan, fadli.personal@gmail.com ${ }^{1)}$, Mardi Hardjianto, \\ mardi.hardjianto@gmail.com ${ }^{2)}$ \\ 1)Program Studi Teknik Informatika, Universitas Bunda Mulia \\ ${ }^{2)}$ Program Studi Teknik Informatika, Universitas Budi Luhur
}

\begin{abstract}
The increasing numbers of Indonesian citizen is followed by with the capability of owning private vehicle, especially car. This increasing number of private vehicle ownership is also followed by the number of car theft. In order to improve the security of private vehicle, this research is focus on designing a security system which using human face as the code to unlock the door. This face recognition system is using algorithm Fisherface and Viola-Jones powered by Android. Fisherface algorithm is a combination between Fisher's Linear Discriminant (FLD) with Principal Component Analysis (PCA). The basic principal of Fisherface algorithm is to reduce the dimension using linear projection. Viola-Jones Algorithm is a step by step algorithm object detection which consist of, Haar-Like Features, Integral Image, Algorithm Adaptive Boosting (AdaBoost) and Cascade of Classifiers combination. This study used those algorithms because look at previous studies, Fisherface algorithm and Viola-Jones combination has good classification, good performance and faster process. The function of this system will help people to increase their car security system and easy to use. Several tests show this system has the accuracy of $90,00 \%$
\end{abstract}

Keywords: Car Locking Door, Face Recognition, Fisherface, Viola-Jones, Andorid, Arduino

\begin{abstract}
ABSTRAK
Peningkatan jumlah penduduk yang disertai dengan perekonomi Indonesia yang semakin membaik berpengaruh pada banyaknya kepemilikan kendaraan bermotor khususnya mobil. Peningkatan jumlah kepemilikan kendaraan bermotor diiringi dengan peningkatan persentase kejahatan seperti tindak pencurian kendaraan bermotor. Untuk meningkatkan keamanan mobil pada penelitian ini akan dibuat sebuah rancang model sistem penguncian pintu pada mobil dengan memanfaatkan pengenalan wajah dengan algoritma Fisherface dan Viola-Jones berbasis Android. Algoritma Fisherface merupakan kombinasi dari metode Fisher's Linear Discriminant (FLD) dengan Principal Component Analysis (PCA). Prinsip dasar algoritma Fisherface adalah mereduksi dimensi menggunakan proyeksi linier. Algoritma Viola-Jones merupakan algoritma pendeteksian obyek yang terdiri dari tahapan, Haar-Like Features, Integral Image, Algoritma pembelajaran berbasis Adaptive Boosting (AdaBoost) dan kombinasi Cascade Of Classifiers. Pemilihan algoritma Fisherface dan Viola-Jones pada penelitian ini dikarenakan dari bebeapa penelitian sebelumnya perpaduan algoritma Fisherface dan Viola-Jones memiliki keunggulan seperti tingkat klasifikasi yang baik, performa yang baik, dan waktu pemrosesan yang lebih cepat. Dengan rancang model pengenalan wajah dengan algoritma Viola-Jones dan Fisherface untuk membuka dan mengunci pintu mobil berbasis Android, diharapkan dapat meningkatkan keamanan pada mobil serta kemudahan dalam pengaplikasiannya. Dari hasil percobaan didapatkan tingkat akurasi sebesar $90,00 \%$.
\end{abstract}

Kata Kunci: Penguncian Mobil, Pengenalan Wajah, Fisherface, Viola-Jones, Andorid, Arduino. 


\section{PENDAHULUAN}

Peningkatan jumlah kepemilikan kendaraan bermotor diiringi dengan peningkatan persentase kejahatan seperti tindak pencurian kendaraan bermotor. Pada data yang dilansir oleh Badan Pusat Statistik (2016, 2017) menunjukkan persentase tindak pencurian kendaraan bermotor pada tahun 2015 dan 2016 masih dalam jumlah yang tingi di indonesia, terutama di daerah-daerah perkotaan ${ }^{[1], ~[2] . ~}$ Penerapan sistem penguncian pintu modern pada mobil ini bertujuan untuk mencegah atau meminimalisir tindakan pencurian mobil. Namun, sistem penguncian pintu modern pada mobil yang ada saat ini masih rentan akan kehilangan, kerusakan atau pencurian. Kehilangan bisa diartikan terjatuh disuatu tempat, tertinggal di suatu tempat, dan tindakan lalai lainnya.

Pada saat ini teknologi biometric menjadi salah satu upaya yang baik untuk dimanfaatkan pada sistem keamanan mobil karena tidak rentan akan kehilangan, kerusakan atau pencurian. Menurut Alisher Kholmatov dan Berrin Yanikoglu (2006) pemanfaatan konsep biometric memiliki kelebihan, seperti kriteria yang unik, sulit untuk ditiru atau dicuri karena mengacu pada ciri fisik seseorang. Pada penelitian ini ciri biometric yang akan digunakan adalah wajah $^{[3]}$.

Ada beberapa algoritma yang dapat digunakan untuk pengenalan wajah, seperti Fisherface yang telah diteliti oleh (Wikrama et al., 2010; Abidin dan Harjoko, 2012) ${ }^{[4],}$ [5]. Algoritma Fisherface merupakan kombinasi dari metode Fisher's Linear Discriminant (FLD) dengan Principal Component Analysis (PCA). Prinsip dasar algoritma Fisherface adalah mereduksi dimensi menggunakan proyeksi linier. Fisherface juga membentuk jarak (scatter) antar kelas terhadap intra. Menurut Belhumeur et al. (1997) semakin besar rasio scatter yang dihasilkan semakin tidak sensitif terhadap perubahan ekspresi ataupun perubahan cahaya, sehingga dapat menghasilkan klasifikasi yang lebih baik ${ }^{[6]}$. Ada pula algoritma pendeteksian objek yang dapat dimanfaatkan untuk proses pendeteksian wajah. (Viola dan Jones, 2001; Wang, 2014) menggunakan algoritma Viola-Jones untuk mendeteksi objek wajah wajah pada sebuah citra ${ }^{[7],[8]}$.

Ada beberapa penelitian yang mengkombinasikan algoritma Fisherface dengan Viola-Jones, seperti penelitian (Qasem dan Younis, 2014; Nguyen et al., 2014) ${ }^{[9], ~}{ }^{[10]}$. Pada penelitian tersebut didapatkan hasil bahwa dengan didahului proses pendeteksian wajah dapat meningkatkan akurasi dan waktu proses pengenalan wajah. Dari hasil penelitian (Belhumeur et al., 2014; Muntasa, 2014; Fernandes dan Bala, 2013) didapatkan keunggulan Fisherface dibanding algoritma lainya pada kondisi tertentu, seperti cepat dalam proses pengenalan dan akurasi yang baik $^{[6],[11],[12]}$.

Pada penelitian ini akan dibuat sistem penguncian pintu pada mobil dengan memanfaatkan pengenalan wajah dengan algoritma Fisherface dan Viola-Jones berbasis Android. Pemilihan algoritma Fisherface pada penelitian ini dikarenakan dari bebeapa penelitian sebelumnya Fisherface memiliki keunggulan seperti tingkat klasifikasi yang baik, performa yang baik, dan waktu pemrosesan yang lebih cepat. Terlebih lagi dengan diawali pendeteksian objek wajah terlebih dulu dengan algoritma Viola-Jones diharapkan keakuratan dan kecepatan akan lebih baik lagi.

Berdasarkan penjabaran latar belakang di atas, terdapat permasalahanpermasalahan utama, yaitu:

1. Banyaknya kepemilikan kendaraan bermotor khususnya mobil tidak diiringi dengan sistem keamanan yang baik.

2. Meningkatnya persentase tindak pencurian kendaraan bermotor khususnya mobil.

3. Belum baiknya sistem penguncian pintu pada kendaraan bermotor khususnya mobil saat ini yang rentan akan kehilangan, kerusakan atau pencurian. 
Tujuan dari penelitian ini adalah membuat sebuah rancang model untuk pengenalan wajah dengan algoritma ViolaJones dan Fisherface untuk membuka atau mengunci pintu mobil berbasis android.

Sentral door lock merupakan sistem terpusat dalam control penguncian pintu. Sistem kontrol mengunci pintu tidak hanya masalah bekerjanya pintu terkunci atau tidak namun juga berbicara masalah kelistrikannya. Sistem control penguncian ada juga yang mempunyai fungsi untuk mendeteksi kunci tertinggal dalam kendaraan. Fungsi ini ditopang oleh berbagai sistem tergantung model dan golongan/kelas. Seperti Gambar 1. yang merupakan bersumber dari Direktorat Pembinaan Sekolah Menengah Kejuruan $(2008)^{[13]}$.

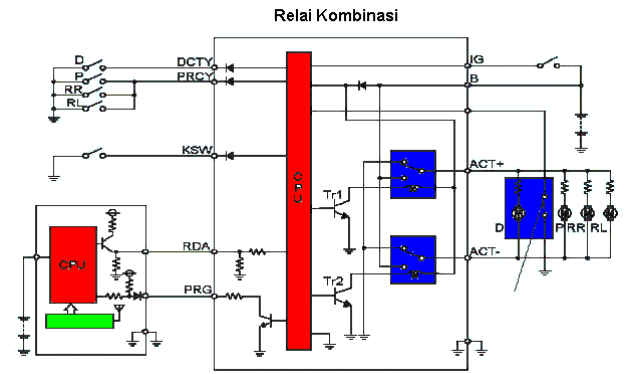

Gambar 1. Rangkaian Sentral Lock .

\section{Pengoperasian dengan Remote Control}

Bila tombol lock/unlock di transmitter ditekan dan bila kunci kontak tidak terpasang di lubangnya dan semua pintu tertutup, maka kendaraan akan mengenali kode dan fungsi kode yang dialirkan. Bila penerima kontrol pintu menerima kode ini, maka CPU di kontrol pintu akan memeriksa dan menentukan. Apabila penerima mengenali kode pintu lock/unlock, maka akan me-ngirimkan sinyal ke relay gabungan. Bila relay gabungan menerima sinyal pintu lock/unlock, maka ia akan menyalakan $\operatorname{Tr} 1$ (untuk mengunci) / Tr 2 (untuk membuka), dan membuat relay lock/unlock menyala. Hasilnya motor di semua pintu kontrol meng-hidupkan sisi lock/unlock.

\section{Operasi mengunci}

ECU Wireless menerima sinyal dengan kode kunci, Relai kombinasi menerima kode dari ECU wireless untuk mengaktifkan $\operatorname{Tr} 1$ supaya relai sentral lock mengaktifkan motor untuk mengunci semua pintu.

\section{Operasi Membuka}

ECU Wireless menerima sinyal dengan kode buka, Relai kombinasi menerima kode dari ECU wireless untuk mengaktifkan $\operatorname{Tr} 2$ supaya relai sentral lock untuk mengaktifkan motor untuk membuka kunci semua pintu.

\section{Pengujian Perangkat Lunak}

Pengujian perangkat lunak menurut Pressman (2012) adalah elemen kritis dari jaminan kualitas perangkat lunak dan mempresentasikan kajian pokok dari spesifikasi, desain dan pengkodean. Selain itu, pengujian juga dapat diartikan sebagai sebuah proses eksekusi suatu program dengan maksud menemukan kesalahan ${ }^{[14]}$.

Strategi dalam pengujian perangkat lunak menyediakan petunjuk yang menjelaskan langkah-langkah yang harus dilakukan sebagai bagian dari pengujian, kapan langkah-langkah ini direncanakan dan kemudian dilakukan, dan berapa banyak usaha, waktu, serta sumber daya yang akan diperlukan dalam pengujian tersebut. Strategi pengujian perangkat lunak selalu menyertakan perencanaan pengujian, perancangan kasus pengujian, pelaksanaan pengujian, dan evaluasi serta pengumpulan data hasil pengujian.

Menurut Pressman (2012) pengujian dalam konteks rekayasa perangkat lunak sebenarnya merupakan rangkaian empat langkah yang diimplementasikan secara berurutan ${ }^{[14]}$ :

Pengujian unit, pengujian fokus pada masing-masing komponen secara individual, dengan memastikan bahwa komponen tersebut berfungsi secara tepat sebagai suatu unit. Pengujian unit menggunakan teknik pengujian dengan menggunakan jalur spesifik di dalam stuktur kontrol dari komponen untuk memastikan cakupan telah lengkap dan dapat mendeteksi kesalahan secara maksimum. 
Pengujian integrasi, membahas isu-isu yang berkaitan dengan dua masalah yaitu verifikasi dan pembangunan program, yang dilakukan dengan teknik perancangan kasus pengujian (test case) yang berfokus pada input dan output. Pengujian integrasi bersumber pada perancangan antarmuka, use case, class diagram, sequence diagram, dan communication diagram.

Pengujian validasi, menyediakan jaminan akhir bahwa perangkat lunak memenuhi semua persyaratan informasi, fungsional, perilaku dan persyaratan kinerja.

Pengujian sistem, memverifikasi bahwa semua elemen saling bertautan dengan benar dan keseluruhan fungsi sistem/kinerja dapat dicapai.

\section{Teknik Pengujian}

Menurut Pressman (2012) setiap produk rekayasa perangkat lunak dapat diuji dalam salah satu kategori pengujian berikut ${ }^{[14]}$ :

Pengujian kotak putih (white-box testing). Dengan mengetahui cara kerja internal suatu produk, pengujian dilakukan untuk memastikan bahwa operasi-operasi internal telah dilakukan sesuai dengan spesifikasi dan semua komponen internal telah dieskusi. White-box testing berfokus pada struktur kendali program.

Pengujian kotak hitam (black-box testing). Dengan mengetahui fungsi yang telah ditentukan, sehingga pengujian dilakukan untuk mencari kesalahan dalam setiap fungsi. Black-box testing dirancang untuk memvalidasi persyaratan fungsional tanpa perlu mengetahui kerja internal dari sebuah program. Teknik pengujian black-box testing berfokus pada ranah informasi dari perangkat lunak, menghasilkan test case dengan cara mempartisi ranah masukan dan keluaran dari sebuah program dengan cara mencakup pengujian yang menyeluruh.

Arduino adalah suatu minimum sistem yang menggunakan Integrated Circuit (IC) dari keluarga AVR dan bersifat open source dengan nama produk Arduino. Arduino menggunakan bahasa pemrograman sendiri yang menyerupai bahasa C. Nama jenis pemrogramannya yaitu bootloader yang telah ditanam di IC mikronya sebelum di jual ke pasaran. Bootloader ini berfungsi untuk penengah antara compiler Arduino dengan mikrokontroler. Untuk melakukan pemrograman menggunakan sofware Arduino IDE. Arduino IDE dibuat dari bahasa pemrograman JAVA. Arduino IDE juga dilengkapi dengan library $\mathrm{C} / \mathrm{C}++$ yang biasa disebut wiring yang membuat operasi input dan outputnya menjadi lebih mudah. Paket Arduino biasanya telah mencakup USB downloader sehingga untuk flash program ke mikrokontroller tinggal langsung menghubungkannya dengan USB komputer / laptop.

Kelebihan yang dimiliki Arduino dibanding mikrokontroller sejenis menurut Arduino.cc (2015) ${ }^{[15]}$ : Sistem arduino sangat terbuka, baik dari sisi hardware dan software-nya. Sangat menarik ketika membuka kotak pembungkus papan arduino terdapat tulisan bahwa arduino diperuntukan bagi seniman, perancang dan penemu. Sungguh membesarkan hati dan membangkitkan semangat bahwa penggunanya tidak harus teknisi berpengalaman ataupun ilmuwan yan jenius.

\section{Penelitian Terkait}

Penelitian Gusanwar dan Bana Handaga pada tahun 2015 dengan judul "Sistem Pembuka Pintu Berbasis Computer Vision dengan Arduino Sebagai Penggerak Actuator". Pada penelitiannya Gusanwar Bana Handaga membandingkan dua algoritma pengenalan wajah yaitu Fisherface dan Eigenface untuk proses pengenalan wajah yang kemudian Arduino digunakan sebagai microcontroller untuk mengendalikan komponen hardware. Pengenalan dilakukan pada 10 foto wajah, masing-masing diambil dari 10 posisi wajah terhadap kamera. Pengujian dilakukan pada ruangan dengan dua kondisi cahaya yang berbeda yaitu dengan dua lampu dan satu lampu. Dan hasilnya hasil menunjukkan bahwa metode Fisherface memiliki performa yang lebih baik dengan tingkat keakuratan $74 \%$ pada ruangan dengan 
kondisi dua lampu (Gusanwar dan Bana, 2015) ${ }^{[16]}$.

Penelitian Guillaume Dave, Xing Chao dan Kishore Sriadibhatla pada tahun 2010 dengan judul "Face Recognition in Mobile Phones". Penelitian tersebut diawali dengan menguji dua algoritma yaitu Eigenface dan Fisherface pada MATLAB. Setelah pengujian tersebut didapatkan akurasi dari masing-masing algoritma, kemudian algoritma dengan akurasi terbaik akan diterapkan pada ANDROID. Algoritma Color Degmentation, Morphological Image Processing dan Template Matching digunakan sebagai deteksi wajah sebelum proses pengenalan wajah. Percobaan terdiri dari 134 gambar dari 10 orang, satu gambar dari setiap orang dijadikan gambar latih dan sisanya dijadikan gambar uji. Dengan nilai threshold sebesar 150 didapatkan tingkat keakurasian paling tinggi yaitu $94 \%$ untuk algoritma Fisherface dan $84 \%$ untuk Eigenface. Dan setelah diterapkan pada ANDROID total waktu proses adalah 1.58 detik (Dave et al., 2010) ${ }^{[17]}$.

Penelitian Rizky Pradana pada tahun 2014 dengan judul "Face Recognition Menggunkan Kombinasi Algoritma ViolaJones dan Principal Component Analysis Dalam Computer Vision". Pada penelitinya Rizky Pradana berusaha memanfaatkan metode pengenalan wajah untuk keamanan sebuah ruangan dalam gedung. Dalam proses pengenalan wajah metode yang digunakan, yaitu Viola-Jones untuk mendeteksi obyek wajah dan PCA untuk mengenali wajah. Rizky Pradana menggunakan pesonal computer pada penelitiannya dengan matlab sebagai tools serta memanfaatkan libarary OpenCV dalam membangun aplikasi. Untuk proses pengenalan wajah diambil masukan dari kamera dengan model input close up dengan menggunakan 40 macam obyek dalam database. Hasil percobaan tesebut adalah tingkat rata-rata keakurasian $94 \%$ (Pradana, 2014) ${ }^{[18]}$.

Penelitian lainnya tentang

Fisherface atau Viola-Jones seperti penelitian Riko Orlando Saragih pada tahun 2015. Penelitian (Riko, 2015) membahas tentang Sistem pengenalan identitas dengan cara membandingkan bobot fisherface yang dibutuhkan untuk merekonstruksi gambar masukan terhadap gambar pada training set. Perhitungan bobot dilakukan dengan metode jarak Euclidian. Pengujian dilakukan terhadap 66 gambar masukan dan tingkat keberhasilan pengenalan wajah sebesar $81,82 \%{ }^{[19]}$.

Penelitian Wikrama et al. (2010) yang berjudul Analisa Penerapan Metode Fisherface Untuk Pengenalan Wajah. Penelitian Wikrama et al. (2010) menggunakan maksimal 11 individu dan minimal 8 individu dengan 16 citra latih dan empat citra uji per individu. Hasil pengujiannya didapati citra yang mengalami perubahan ekspresi dengan pencahayaan normal diperoleh akurasi sistem $97,73 \%$. Citra yang mengalami perubahan pencahayaan diperoleh akurasi sistem $63,64 \%{ }^{[4]}$.

Penelitian Qasem dan Younis (2014) mengkombinasikan metode Fisherface dan Viola-Jones. Tujuan penelitian menghitung waktu proses pengenalan gambar pada empat varian design arsitektur RTFRS, yaitu CPU Mono Face Recognition, CPU Parallel Face Recognition, Hybrid Mono Face Recognition, Hybrid Parallel Face Recognition. Percobaan terdiri dari 400 gambar untuk wajah 40 orang (10 gambar per orang). Spesifikasi hardware laptop komputer sama processor i7 core Intel 2,2 GHz , Nvidia GPU GeForce GT 630M, RAM 7GB. Hasil dari percobaan didapatkan CPU Parallel Face Recognition 71 kali lebih cepat, Hybrid Mono Face Recognition 72.04 kali lebih cepat dan Hybrid Parallel Face Recognition 80 kali lebih cepat dari model CPU Mono Face Recognition ${ }^{[9]}$.

Penelitian Abidin dan Harjoko (2012) mengkombnasikan beberapa metode seperti Integral Projection, Fisherface dan Learning Of Backpropagation Neural Netrowk untuk mengenali ekspresi wajah seseorang. Percobaan terdiri dari 140 gambar latih dan 73 gambar uji untuk setiap percobaan. Feed Foward Neural Network digunakan untuk 
mengklasifikasikan gambar ekspresi wajah dan pengenalan/pencocokan dengan Fisherface. Integral projection method digunakan untuk membuat face localization. kemudian, wajahnya dipotong dan ukuran gambar dinormalisasi ke $33 \times$ 29 piksel. Evaluasi kinerja sistem pengenalan ekspresi wajah menggunakan dua parameter, yaitu recognition rate and false positive rate.Rata-rata akurasi yang dihasilkan $89,2 \%{ }^{[5]}$.

Penelitian Shun et al. (2002) memanfaatkan metode fisherface untuk pengenalan wajah dengan percobaan pada 350 subyek wajah, dengan masing-masing subyek wajah ada 5 gambar. 1 gambar masing-masing subyek digunakan untuk data latih dengan kondisi posisi frontal, ekspresi wajah netral dan kondisi cahaya normal. 4 gambar dari masing-masing subyek sebagai gambar uji jadi ada 1400 gambar uji dengan variasi pada ekspresi wajah, pencahayaan dan poisisi wajah menghadap. Hasil dari pengujian didapatkan akurasi yang dihasilkan $87.9 \%$ [20]

Penelitian Nguyen et al. (2002) mengkombinasikan metode Haar Features dan Fisherface yang dimanfaatkan untuk otentifikasi seseorang. Tahap otentifikasi dilakukan dengan dua validasi pertama dengan RFID kedua dengan pengenalan wajah. Percobaan penggunakan database yang berisi 1.000 gambar terdiri dari gambar wajah dan non-wajah. Masingmasing dibagi menjadi data latih 500 gambar dan data uji 500 gambar. Data uji terdiri dari 250 gambar wajah dan 250 gambar non-wajah, dimana semua dinormalisasi dengan ukuran yang sama dari $200 \times 200$ piksel. Untuk data latih dikondisikan dengan posisi frontal, pencahayaan yang berbeda dengan nuansa yang berbeda dan ekspresi bahagia, sedih, marah dan lain sebagainya. Hasil dari percobaan akurasi yang dihasilkan $91.3 \%$ [10].

Banyaknya kepemilikan mobil diiringi dengan peningkatan persentase pencurian mobil. Sehingga perlu adanya perbaikan pada sisi keamanan mobil dalam hal ini akan dibahas dari segi sistem penguncian pintu mobil.

Salah satu cara pengamanan mobil khususnya pada sistem penguncian pintu mobil perlu dikembangkan, yaitu sistem penguncian pintu mobil berdasarkan pengenalan wajah untuk menghindari kerusakan, kehilangan atau pencurian.

Diusulkan model pengenalan wajah dengan algoritma Viola-Jones dan Fisherface untuk membuka dan mengunci pintu mobil berbasis Android.

Design model pengenalan wajah dengan algoritma Viola-Jones dan Fisherface untuk membuka dan mengunci pintu mobil berbasis Android yang diusulkan akan digambarkan alurnya menggunakan flowchart dan design tersebut akan diimplementasikan ke dalam model menggunakan Android Program dan library OpenCV.

Penerapan metode pengenalan wajah pada sistem penguncian pintu mobil diharapkan mampu meningkatkan keamanan mobil karena hanya pemilik yang otentik yang dapat membuka atau mengunci pintu mobil.

\section{METODOLOGI DAN RANCANGAN PENELITIAN}

Metode penelitian yang digunakan dalam penelitian ini adalah metode eksperimen. Eksperimen pada penelitian ini bertujuan untuk mendeteksi dan mengenali wajah seseorang dengan menggunakan algoritma Viola-Jones dan Fisherface. Dengan metode ini proses pendeteksian dilakukan saat wajah seseorang menghadap kamere smartphone Android, kemudian citra wajah yang terdeteksi akan diambil untuk dilanjutkan pada proses perhitungan. Proses perhitungan adalah menghitung kesamaan ciri wajah yang baru diambil dengan data wajah yang sudah tersimpan. Hasil perhitungan akan dianalisis untuk disimpulkan tingkat kesamaannya. Kesemua proses pada penelitian ini bertujuan untuk menghasilkan model pengenalan wajah dengan algoritma Viola- 
Jones dan Fisherface untuk membuka dan mengunci pintu mobil berbasis Android.

Pemilihian sampel berdasar pada metode Quota Sampling karena sampel yang diambil berdasar pada kebutuhan penelitian ini dan telah ditentukan kriteria atau kondisinya. Sampel dalam penelitian adalah citra wajah dengan kondisi sudut wajah $0^{\circ}$ terhadap kamera, pemakain beberapa aksesoris disekitar muka dan pencahayaan mencukupi. Dari kondisi diatas akan diambil 6 data citra wajah training ditambah 7 data citra wajah testing yang digunakan sebagai sampel dalam penelitian ini.

Untuk mendapatkan data dalam penelitian ini digunakan beberapa metode pengumpulan data observasi, yaitu metode pengumpulan data dengan pengamatan langsung. Data citra wajah training diambil dari orang-orang disekitar peneliti dengan kondisi yang diingikan dalam penelitian ini. Data citra wajah negativ diambil dari orangorang disekitar peneliti dengan kondisi yang diinginkan penulis diluar ketentuan kondisi yang diinginkan dalam penelitian ini. Kondisi yang dimaksud adalah kondisi sudut wajah $0^{\circ}$ terhadap kamera, pemakain beberapa aksesoris disekitar muka dan pencahayaan mencukupi.

Pada penelitian ini digunakan dua kelompok data dari sampel, pertama kelompok data latih (training data set) yaitu 6 data citra wajah pemilik kendaraan yang digunakan sebagai sampel. Kelompok data yang kedua adalah kelompok data uji (testing data set) yaitu 7 data citra wajah pemilik kendaraan dan selain pemilik kendaraan yang digunakan sebagai sampel.

\section{Rancang Model Pengenalan Wajah}

Gambar 2 menunjukkan cara kerja model. Berikut penjelasan lebih lanjut tentang cara kerja model:
a. Pengguna menghadapkan wajahnya ke kamera depan Smartphone
b. Smartphone melakukan proses Recognition terhadap citra wajah

c. Jika proses recognition berhasil smartphone akan mengirim sinyal " 1 " ke signal receiver jika gagal maka pesan akan muncul dilayar.

d. Signal receiver meneruskan sinyal ke Arduino

e. Arduino memproses sinyal hingga menggerakan motor pintu

f. Setelah motor bergerak Arduino mengirim sinya "sukses" ke signal receiver yang diteruskan ke Smartphone dan ditampilkan kelayar

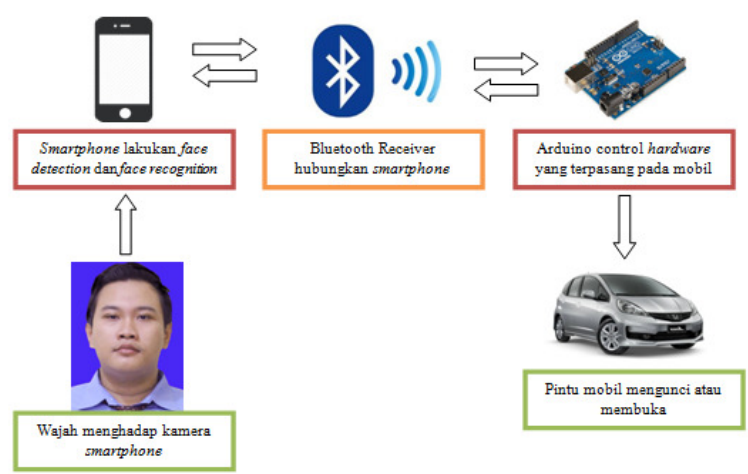

Gambar 2. Cara Kerja Model

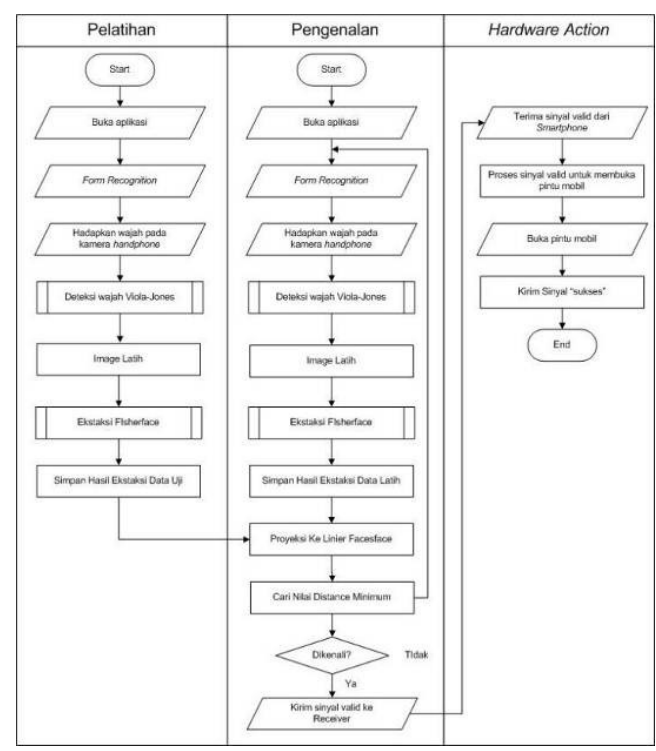

Gambar 3. Cara Proses Model

Aplikasi ini terbagi menjadi dua proses pengenalan wajah dan Hardware Action. Proses pengenalan wajah terbagi menjadi dua bagian, yaitu proses pelatihan 
dan proses pencocokan. Pada proses pelatihan terdapat beberapa tahap yang dilakukan yaitu deteksi wajah, penyelarasan wajah, penyimpanan citra wajah ke dalam database, ekstraksi fitur dan penyimpanan hasil ekstraksi. Proses pencocokan memiliki beberapa tahapan yang sama seperti proses pelatihan, perbedaannya hanyalah pada proses pencocokan, karena tahapan ini adalah inti dari pengenalan wajah. Hardware Action yang dimaksud adalah bagaimana Arduino yang digunakan sebagai microcontroller dapat mengendalikan komponen hardware untuk membuka dan mengunci pintu mobil. Setelah Arduino berhasil mengendalikan komponen hardware untuk membuka dan mengunci pintu mobil kemudian mengirim sinyal "Sukses" kembali ke Smartphone. Gambar 3 menunjukan alur kerja aplikasi:

\section{HASIL PENELITIAN}

Langkah pertama dalam percobaan ini adalah menyiapkan perangkat keras seperti, smartphone dengan spesifikasi, RAM 2GB, kamera depan dengan resolusi layer $5 \mathrm{mp}$. Langkah kedua adalah memilih orang-orang yang akan melakukan percobaan. Pada penelitian ini akan dipilih 6 orang yang akan melakukan percobaan, terdiri dari 2 orang wanita dan 5 orang pria termasuk peneliti. Orang-orang yang dipilih berparameter usia antara 7 tahun sampai 55 tahun, berkulit kuning langsat atau sawo matang.

Sesuai dengan batasan masalah, maka pengujian hanya dilakukan terhadap wajah yang menghadap lurus atau $0^{\circ}$ terhadap kamera. Jarak kamera terhadap objek wajah dibatasi antara $20 \mathrm{~cm}$ sampai dengan $30 \mathrm{~cm}$ hal ini didasarkan kenyamanan pengguna karena aplikasi ini digunakan oleh 1 orang. Berikut adalah data citra wajah yang akan dijadikan data training:

Testing citra wajah akan dilakukan oleh orang-orang yang sama dengan orangorang yang melakukan training citra wajah, namun pada kondisi dan waktu yang berbeda. Testing citra wajah juga akan ditambah 1 citra wajah selain orang yang melakukan training citra wajah.

Tabel 1. Citra Wajah Training

\begin{tabular}{|c|c|c|c|}
\hline No. & $\begin{array}{c}\text { Gambar } \\
\text { pada } \\
\text { kamera }\end{array}$ & $\begin{array}{l}\text { Citra yang } \\
\text { ditangkap }\end{array}$ & Keterangan \\
\hline 1. & & & $\begin{array}{l}\text { Laki-laki } \\
\text { usia } 24 \\
\text { tahun, kulit } \\
\text { sawo } \\
\text { matang }\end{array}$ \\
\hline 2. & & & \begin{tabular}{l}
\multicolumn{2}{l}{ Perempuan } \\
usia \\
tahun, \\
warna kulit \\
sawo \\
matang
\end{tabular} \\
\hline 3. & & & \begin{tabular}{ll}
\multicolumn{2}{l}{ Perempuan } \\
usia \\
tahun, \\
warna \\
sawo \\
matang
\end{tabular} \\
\hline 4 & & & $\begin{array}{l}\text { Laki-laki } \\
\text { usia } \\
\text { tahun, } \\
\text { warna kulit } \\
\text { sawo } \\
\text { matang }\end{array}$ \\
\hline 5. & & & $\begin{array}{l}\text { Laki-laki } \\
\text { usia } 33 \\
\text { tahun, kulit } \\
\text { sawo } \\
\text { matang }\end{array}$ \\
\hline 6. & & 2 & $\begin{array}{l}\text { Laki-laki } \\
\text { usia } 30 \\
\text { tahun, kulit } \\
\text { sawo } \\
\text { matang }\end{array}$ \\
\hline
\end{tabular}

Pada aplikasi yang dibuat akan dibatasi toleransi nilai Eucledean Distance mulai dari 0 sampai dengan 10 ( $0<$ Eucledean Distance < 10). Hal ini dikarenakan aplikasi diperuntukan untuk keamanan mobil, mengamati percobaan 
yang telah dilakukan pada tabel IV.2, jika pengenalan berhasil nilai Eucledean Distance selalu dibawah 10. Dengan hal tersebut testing nomer 7 akan dinyatakan tidak dikenali. Aplikasi tidak akan mengirim sinya " 1 " ke aduino untuk membuka pintu mobil. pada aplikasi ini penggunaan aksesoris sekitar wajah akan memperbesar nilai Eucledean Distance, untuk itu aplikasi ini membatasi penggunaan aksesoris disekitar wajah.

Tabel 2. Citra Wajah Testing

\begin{tabular}{|c|c|c|c|c|}
\hline No & Wajah Testing & Wajah dikenali & $\begin{array}{c}\text { Euclidean } \\
\text { distance }\end{array}$ & Ket. \\
\hline 1. & & & 5.349 & $\begin{array}{l}\text { Dianggap } \\
\text { berhasil } \\
\text { karena wajah } \\
\text { testing sesuai } \\
\text { dengan } \\
\text { training }\end{array}$ \\
\hline 2. & & & 6.598 & $\begin{array}{l}\text { Dianggap } \\
\text { berhasil } \\
\text { karena wajah } \\
\text { testing sesuai } \\
\text { dengan } \\
\text { training }\end{array}$ \\
\hline 3. & & & 5.657 & $\begin{array}{l}\text { Dianggap } \\
\text { berhasil } \\
\text { karena wajah } \\
\text { testing sesuai } \\
\text { dengan } \\
\text { training }\end{array}$ \\
\hline 4. & & & 4.798 & $\begin{array}{l}\text { Dianggap } \\
\text { berhasil } \\
\text { karena wajah } \\
\text { testing sesuai } \\
\text { dengan } \\
\text { training }\end{array}$ \\
\hline 5. & & & 4.581 & $\begin{array}{l}\text { Dianggap } \\
\text { berhasil } \\
\text { karena wajah } \\
\text { testing sesuai } \\
\text { dengan } \\
\text { training }\end{array}$ \\
\hline 6. & & & 5.578 & $\begin{array}{l}\text { Dianggap } \\
\text { berhasil } \\
\text { karena wajah } \\
\text { testing sesuai } \\
\text { dengan } \\
\text { training }\end{array}$ \\
\hline 7. & & & 10.247 & $\begin{array}{l}\text { Dianggap } \\
\text { berhasil } \\
\text { karena wajah } \\
\text { testing } \\
\text { memang tidak } \\
\text { ada pada } \\
\text { wajah training }\end{array}$ \\
\hline 8. & & & 12.564 & $\begin{array}{l}\text { Dianggap } \\
\text { gagal karena } \\
\text { wajah testing } \\
\text { ada pada } \\
\text { wajah } \\
\text { training, tetapi } \\
\text { nilai } \\
\text { Euclidean } \\
\text { distance diatas } \\
\text { ambang batas }\end{array}$ \\
\hline 9. & & & 5.952 & $\begin{array}{l}\text { Dianggap } \\
\text { berhasil } \\
\text { karena wajah } \\
\text { testing sesuai } \\
\text { dengan } \\
\text { training }\end{array}$ \\
\hline 10. & & 70 & 6.246 & $\begin{array}{l}\text { Dianggap } \\
\text { berhasil } \\
\text { karena wajah } \\
\text { testing sesuai } \\
\text { dengan } \\
\text { training }\end{array}$ \\
\hline
\end{tabular}

Percobaan ke 1 sampai dengan 6 berjalan dengan sesuai ketentuan penelitian ini begitu juga percobaan ke 9 dan 10 dianggap berhasil karena wajah testing sesuai dengan training. Percobaan 7 juga dianggap berhasil karena wajah testing memang tidak ada pada wajah training. Percobaan 8 dianggap gagal karena wajah testing ada pada wajah training, tetapi nilai Euclidean distance diatas ambang batas.

Implikasi yang ditimbulkan dari penelitian ini meliputi beberapa aspek, diantaranya adalah aspek sistem, aspek manajerial dan aspek penelitian lanjutan. Penjelasan implikasi pada aspek sistem adalah penelitian yang dibuat dapat ditinjau dari beberapa kategori, yaitu Strategik, Taktis dan Operasional. Penelitian yang dibuat dapat ditinjau dari kategori Organisasi, Sumber Daya Manusia, Pendidikan Pengguna, Pelatihan Pengguna dan Regulasi yang ada merupakan penjelasan dari impilkasi pada aspek manajerial. Sedangkan penjelasan implikasi pada aspek penelitian lanjutan adalah penelitian dapat ditinjau dari ruang lingkup pengembangan metode yang digunakan atau peningkatan infrastruktur dari hasil penelitian yang telah dibuat.

Penelitian ini mempunyai arti sesuai dengan kegunaannya sebagai sistem otentifikasi pemilik mobil yang dapat akses untuk membuka atau menutup pintu mobil. Tujuan penelitian ini, yaitu terpenuhinya efektifitas dan efisiensi dalam keamanan mobil dapat diperoleh dengan penerapan yang tepat.

Teknik operasional sistem yang terdiri dari hardware dan software juga termasuk hal yang dibahas dalam aspek sistem. Terbentuknya suatu hasil penelitian yang tidak memakan banyak biaya tetapi mempunyai kinerja yang maksimal merupakan implikasi yang ditimbulkan pada aspek ini. Hal ini terbukti dari spesifikasi yang dibutuhkan dalam penerapan hasil penelitian ini yang cenderung tidak memerlukan hardware dan software yang mahal/lebih ekonomis. 
Aspek manajerial yang ditinjau dari bidang organisasi, penerapan metode ini dalam suatu sistem keamanan untuk otentifikasi pemilik kendaraan cukup membantu, karena penggunaan aplikasi cukup mudah. Aplikasi juga dapat dipakai banyak masyarakat karena Smartphone berbasis Android sudah banyak dimiliki masyarakat Indonesia. Penggunaan aplikasi ini dapat membantu pemerintah dalam pencegahan pencurian kendaraan bermotor.

Implikasi hasil penelitian dalam aspek penelitian lanjutan dapat dikelompokkan dalam beberapa ruang lingkup, diantaranya adalah:

\section{Aspek Metode}

Aspek metode ini dapat dilakukan dengan penambahan atau penggantian metode yang digunakan untuk memperoleh hasil yang lebih baik lagi. Aspek ini penambahan metode dapat dilakukan dari segi pendeteksian citra wajah atau dari segi pengenalan citra wajah.

\section{Aspek Hardware dan Objek}

Aspek hardware dan objek penelitian lanjutan yang dapat dilakukan antara lain dengan:

a. Pengenalan dengan format tiga dimensi.

b. Peningkatan kualitan kamera yang digunakan untuk pendeteksian dan pengenalan wajah.

c. Peningkatan kualitas smartphone yang digunakan dalam proses pendeteksian citra wajah dan pengenalan citra wajah agar dapat meningkatkan performa dan memangkas waktu proses.

d. Perubahan arsitektur hardware yang digunakan agar proses pengenalan dapat dilakukan pada mikrokontroler.

e. Pemanfaatan aplikasi dapat dikembangkan lagi untuk fungsi lainnya, seperti starter mobil dan lainlain.

\section{Rencana Implementasi}

Setelah dilakukan penelitian untuk Prototipe Pengenalan Wajah Untuk Sistem
Penguncian Pintu Mobil Berasis Android, selanjutnya akan dirancang rencana implementasi sebagai berikut:

a. Melakukan perbaikan aplikasi bertujuan untuk melengkapi fungsi dari fitur-fitur aplikasi berdasarkan saran atau masukan dari tim penguji demi menunjang fungsionalitas dari sistem.

b. Melakukan penyempurnaan dari segi alur penggunaan bertujuan agar aplikasi siap untuk dilepas ke msyarakat.

c. Melakukan promosi aplikasi bertujuan agar aplikasi tersebut dikenal dan digunakan masyarakat secara luas dengan cara memperkenalkan kelingkungan peneliti terlebih dahulu.

d. Evaluasi bertujuan untuk menguji sistem ini apakah berjalan sesuai dengan yang diharapkan atau tidak.

e. Melakukan perbaikan atas hasil evaluasi ditujukan agar fitur-fitur aplikasi yang tidak berjalan sesuai fungsinya dapat dibenahi atau diperbaiki.

Maintenance merupakan tahapan dari rencana implementasi yang harus diperhatikan agar fungsi dari sistem tetap berjalan sebagaimana mestinya.

\section{SIMPULAN}

\section{Simpulan}

Aplikasi dengan memanfaatkan perkembangan teknologi komputer yaitu dengan Prototipe Pengenalan Wajah untuk Sistem Penguncian Pintu Mobil Berbasis Android dapat membantu meningkatkan keamanan mobil.

Dengan dibuatnya Prototipe Pengenalan Wajah Dengan Algoritma Fisherface dan Viola-Jones Untuk Sistem Penguncian Pintu Mobil Berasis Android ini diharapkan dapat menurunkan persentase pencurian kendaraan bermotor karena membaiknya sistem keamanan mobil.

Dengan dibuatnya Prototipe Pengenalan Wajah Dengan Algoritma Fisherface dan Viola-Jones Untuk Sistem Penguncian Pintu Mobil Berasis Android 
ini diharapkan dapat menggantikan sistem penguncian yang ada saat ini yang masih rentan akan kehilangan, kerusakan atau pencurian.

Akurasi pada Prototipe Pengenalan Wajah Dengan Algoritma Fisherface dan Viola-Jones Untuk Sistem Penguncian Pintu Mobil Berasis Android sebesar 90, $00 \%$ dan kecepatan proses kurang dari 1 detik.

\section{Saran}

Dapat dikembangkan lagi Aplikasi Pengenalan Wajah Untuk Sistem Penguncian Pintu Mobil Berbasis Android yang dapat memproses gambar 3 dimensi.

Aplikasi pengenalan Wajah Untuk Sistem Penguncian Pintu Mobil Berbasis Android juga dapat diterapkan untuk aspek lain dari kemanan lain seperti untuk starting engine pada mobil.

Hasil penelitian ini akan dievaluasi kembali setelah diuji coba dilingkungan peneliti kemudian disempurnakan dan selanjutnya aplikasi ini akan pasarkan bersamaan dengan Arduino yang akan dipasang pada mobil.

Implikasi yang timbul dari penelitian ini, cenderung tidak memerlukan hardware dan software ekonomis, penggunaan aplikasi cukup mudah dan perpaduan meode Fisherface dan ViolaJones baik dalam pengenalan wajah, ditunjang kualitas kamera yang baik akan meningkatkan akurasi pengenala.

\section{DAFTAR PUSTAKA}

[1] Badan Pusat Statistik, "Statistik Kriminal Tahun 2016," Jakarta, vol. 04330.1601, 2016.

[2] Badan Pusat Statistik, "Statistik Kriminal Tahun 2017," Jakarta, vol. 04330.1701, 2017.

[3] A. Kholmatov and Berrin Yanikoglu, "Biometric cryptosystem using online signatures," Sabanci Univ., 2006.

[4] C. G. N. Wikrama, T. A. B. Wirayuda, and T. Brotoharsono,
"ANALISA PENERAPAN METODE FISHERFACE UNTUK PENGENALAN WAJAH," Univ. Telkom, 2010.

[5] Z. Abidin and A. Harjoko, "A Neural Network based Facial Expression Recognition using Fisherface," vol. 59, no. 3, pp. 3034, 2012.

[6] P. N. Belhumeur, J. P. Hespanha, and D. J. Kriegman, "Eigenfaces vs. $\sim\{$ Fisherfaces $\}$ : Recognition using class specific linear projection," Pami, vol. 19, no. 7, pp. 711-720, 1997.

[7] P. Viola and Michael Jones, "Rapid object detection using a boosted cascade of simple features," Proc. 2001 IEEE Comput. Soc. Conf. Comput. Vis. Pattern Recognition. CVPR 2001, vol. 1, 2001.

[8] Y. Wang, "An Analysis of the Viola-Jones Face Detection Algorithm," Ipol, Issn, vol. 4, pp. 128-148, 2014.

[9] Z. Qasem Jaber and M. Issam Younis, "Design and Implementation of Real Time Face Recognition System (RTFRS)," Int. J. Comput. Appl., vol. 94, no. 12, pp. 15-22, 2014.

[10] T. D. Nguyen, Lam Duong Quang, Nhat Cao Van, L. T. Thanh, T. M. Hoang, and T. de Souza-Daw, "An efficient and reliable human resource management system based on a hybrid of face authentication and RFID technology," 2012 Fourth Int. Conf. Commun. Electron., no. September 2015, pp. 333-338, 2012.

[11] A. Muntasa, "New Modelling of Modified Two Dimensional Fisherface Based Feature Extraction," TELKOMNIKA (Telecommunication Comput. Electron. Control., vol. 12, no. 1, p. 115, 2014. 
[12] S. Fernandes and J. Bala, "Performance Analysis of PCAbased and LDA-based Algorithms for Face Recognition," Int. J. Signal Process. Syst., vol. 1, no. 1, pp. 1-6, 2013.

[13] Direktorat Pembinaan Sekolah Menengah Kejuruan, "SISTEM ALARM CENTRAL," Jakarta, pp. 475-490, 2008.

[14] R. S. Pressman, Software Engineering A Practitioner's Approach Seventh Edition, Seventh Ed. The McGraw-Hill Companies, Inc, 2012.

[15] www.Arduino.cc, "Introduction Arduino," 2015. [Online]. Available: https://www.arduino.cc/en/Guide/Int roduction. [Accessed: 29-Sep-2015].

[16] Gusanwar and B. Handaga, "SISTEM PEMBUKA PINTU BERBASIS COMPUTER VISION DENGAN ARDUINO SEBAGAI PENGGERAK ACTUATOR,"
Univ. Muhammadiyah, Surakarta, 2015.

[17] G. Dave, X. Chao, and K. Sriadibhatla, "Face Recognition in Mobile Phones," Dep. Electr. Eng. Stanford Univ. Stanford, USA, 2010.

[18] R. Pradana, "Face Recognition Menggunkan Kombinasi Algoritma Viola-Jones dan Principal Component Analysis Dalam Computer Vision," Jakarta: Universitas Budi Luhur, 2014.

[19] S. Riko Arlando, "Pengenalan Wajah Menggunakan Metode Fisherface," J. Tek. Elektro, vol. 7, no. 1, pp. 50-62, 2007.

[20] S. Shun, B. Cao, W. Gao, and D. Zhao, "Extended Fisherface for Face Reocognition From A Single Example Image Per Person," Inst. Comput. Technol. Chinese Acad. Sci. China, 